\title{
BENDING-TESTING OF ARROWS
}

\author{
Levente PÉCSI ${ }^{1}$, Judit PÁSZTOR ${ }^{2}$, András KAKUCS ${ }^{3}$ \\ ${ }^{1}$ VIVA COM Srl., Târgu Mureş, Romania, pecsi_levente@yahoo.com \\ ${ }^{2,3}$ Sapientia University, Faculty of Technical and Humanities Science, Târgu Mureş, Romania \\ ${ }^{2}$ pjudit@ms.sapientia.ro \\ ${ }^{3}$ kakucs2@ms.sapientia.ro
}

\begin{abstract}
Archery is a tradition, a style of martial arts and a competitive sport, while at the same time being an art form. The equipment consists of a bow and arrows. The deflection of the arrow is a very important characteristic, one which has a decisive influence on how and if the arrow reaches the target. This has a tremendous impact on the performance of the archer in both competition and archery demonstrations. The quantification and measurement of arrow deflection is equally important to both manufacturers and archers. It is affected by the arrow's static bending. In this paper the bend of the arrow shall be determined.
\end{abstract}

Keywords: bow, arrow, bend, spine.

\section{Introduction into the theory of arc- hery}

Archery is the activity of using a bow to propel arrows. The bow and the arrow first appeared in the Paleolithic era. Initially, selfbows were used, which were very similar to the English longbows used in our time. They had great importance in hunting and in battles, helped many nations to conquer the world. Nowadays, archery lives on as a sporting activity. The basic accessories of archery are the bow and arrows. The bow is a curved flexible object. All bows consist of a string attached to elastic limbs that store mechanical energy as the user draws the string backwards.

Throughout history bows were divided into longbows and composite bows. The evolution of technology has resulted in the following bow types: traditional or historical bows, the bowhunter recurve and barebow, the Olympic bow, the compound bow and the crossbow. The composition of the bow can be seen in Figure 1.

The parts of the arrow can be seen in Figure 2.

The arrow shaft is usually made of wood, fiberglass, aluminum or carbon fiber. The classification of arrows is made by regarding their diameter, stiffness and quantification. The traditional

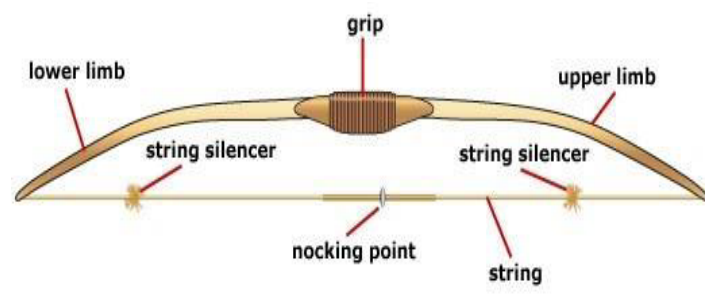

Figure 1. The structure of a longbow [1]

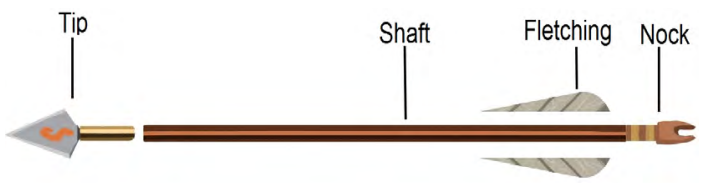

Figure 2. The structure of an arrow

combat instruments used by different ethnic groups vary in shape and size, so the sport archery brings all this together and partially standardizes them.

\section{Theory of archery}

The bow is a simple machine. It is made from a hard material, united at both ends by a string. Tensioning the string results in bending in the parts of the bow called the limbs. When the string 
is released, it tries to regain its resting position as quickly as possible, thereby releasing an arrow at a right angle to it, delivering some of the potential energy of the bow's stretched limbs to the arrow, thereby increasing its velocity. The arrow follows the principle of free-throwing to reach the goal.

Reaching the target can be influenced by many things, such as the material of the bow, its structure, the draw weight, the draw length, pre-tensioning, and bending height. The most important thing is the profile of the arrow, its stiffness and it's mass. But the archer is also important, as is the environment. The success of the archer depends on pairing the right pieces of equipment in every situation. That is why it is so important to know the bow and the arrows well.

When choosing the right arrow, the spine is very important.

The bend of the arrow, the static spine, is important information because through it we can estimate the dynamic spine generated by shooting. Bending is the phenomenon of instability of the pressed arrow, where the arrow is bent over the excessive axial thrust, based on [2]. The bend allows the arrow to stay on the right track, Figure 3. Indirectly this characteristic can be deduced from the stiffness and rigidity of the arrow which affects the direction of the arrow.

Knowing the arrows stiffness helps the archer to pair the bow with suitable arrows. Arrow stiffness is measured with a device that measures the deflection of it, in the archery slang it is called the spine-tester.

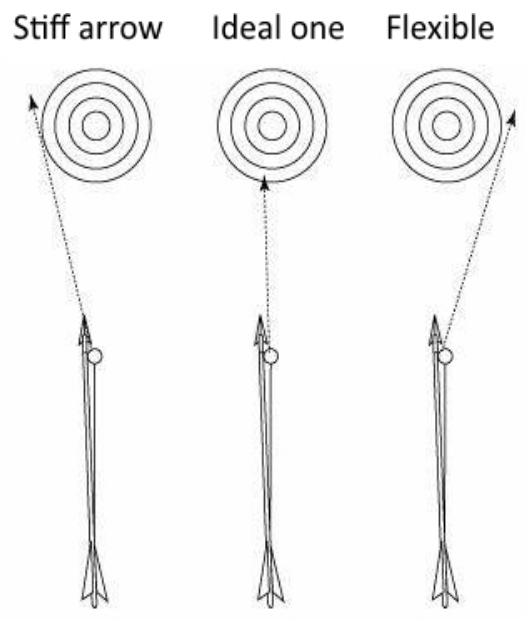

Figure 3. Arrows stiffness' effect

\section{Measurement and data processing}

The measuring apparatus that was realized for measuring arrows stiffness is presented in Figure 4.

The method of measurement: the arrow shaft is supported at two points and statically loaded perpendicular to the arrows axis at the half distance between the support points. The distance between the support points and the weight used to load the center of the arrow depends on the material of the arrow. We measure the magnitude of deflection between loaded and unloaded states and deduce the difference, Figure 5.

The deflection value is determined by the AMO standard according to the Archery Manufacturers Organization: the arrow is placed on two supporting points which are $d 1=26$ inches apart from each other, and its middle point is loaded with M1= 2 pounds, 907.2 grams, Figure 5. The distance between the original position at the center of the arrow and the position of the loaded position, determines the deflection value that is expressed in inches and is determined by the AMO standard for this spine. Deflection and spine matching using the AMO standard is shown in Figure 6. This standard is valid for wooden arrows.

When weighing the carbon and aluminum-carbon arrows, the method of measurement varies, $\mathrm{d} 2=28$ inches distance between the supports and

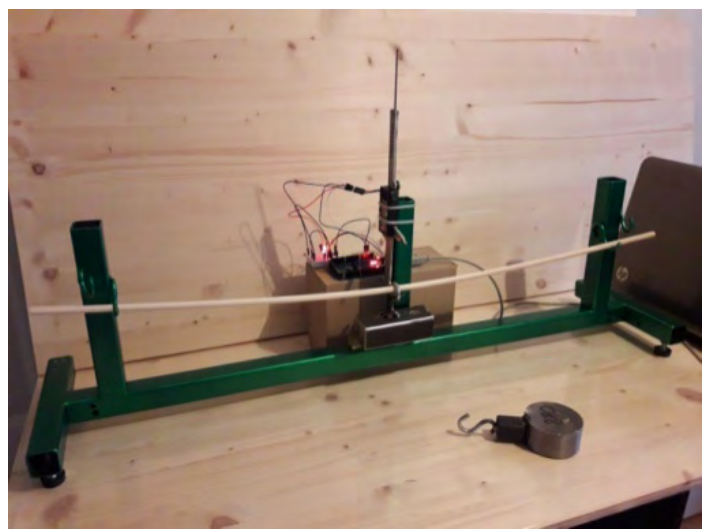

Figure 4. The spine-tester

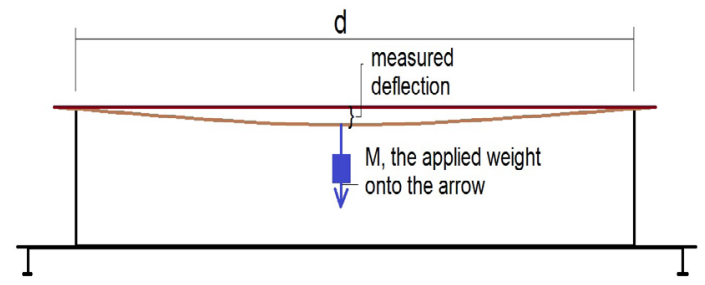

Figure 5. Arrows stiffness' effect 
1.94 pounds of mass, M2 = 880 grams of load. In this case, the difference between the two end positions measured at the center of the shaft is multiplied by 1000 , the obtained value is rounded and the spine is mapped according to Figure 7.

The significance of the deflection factor was noted in the middle of the last century by American fletchers, manufacturers and they tried to qualify and mark them. The standard was primarily used to measure wooden arrows, which meant their stiffness, and a discrete value is described as a nonlinear relationship, Figure 6. The stiffer the shaft the greater the deflection factor. This proved to be misleading with arrows made from modern materials, so they were already sorted into intervals and measured the arrows flexibility. One is the inverse of the other, so in this case, unlike the former, the stiffer the arrow, the smaller the deflection factor, Figure 7.

In both cases - of arrows made of wood or modern material - the universally accepted and used term, the English term "spine” denotes the stiffness of the arrows. Those skilled in both metrics understand the meaning of the word spine from the context, but it is very misleading for lay people, as it may be the rigidity but also flexibility.

We have measured two series of wooden and two series of carbon arrows, each turned three times at $45^{\circ}$. The data and calculations were recorded in a table. Due to the extent of the tables, only one part is presented in Table 1.

When evaluating the data, we determined the confidence intervals of the deflection of the arrow series with $95 \%$ probability, based on [3]. The data is shown in Table 2.
Table 2. Arrow deflection estimation for wooden and carbon arrows

\begin{tabular}{|c|c|c|c|c|c|c|}
\hline \multirow{2}{*}{$\begin{array}{c}\text { Arrow } \\
\text { mate- } \\
\text { rial }\end{array}$} & \multirow{2}{*}{$\mathbf{n}$} & \multirow{2}{*}{$\begin{array}{l}\text { Measure- } \\
\text { ments } \\
\text { average } \\
\text { [inch] }\end{array}$} & \multirow{2}{*}{\begin{tabular}{|c}
$\begin{array}{c}\text { Experi- } \\
\text { mental } \\
\text { devia- } \\
\text { tion }\end{array}$ \\
\end{tabular}} & \multirow[b]{2}{*}{$\mathbf{t}_{0.05}$} & \multicolumn{2}{|c|}{$\begin{array}{c}\text { Estimated } \\
\text { value }\end{array}$} \\
\hline & & & & & $\begin{array}{c}\text { Lower } \\
\text { limit }\end{array}$ & \begin{tabular}{|c|} 
Upper \\
limit
\end{tabular} \\
\hline \multirow{2}{*}{ Wood } & 12 & 0.990 & 0.064 & 2.201 & 0.950 & 1.031 \\
\hline & 14 & 0.547 & 0.018 & 2.160 & 0.537 & 0.558 \\
\hline \multirow{2}{*}{ Carbon } & 7 & 0.582 & 0.009 & 2.447 & 0.573 & 0.590 \\
\hline & 6 & 0.708 & 0.010 & 2.571 & 0.697 & 0.719 \\
\hline
\end{tabular}

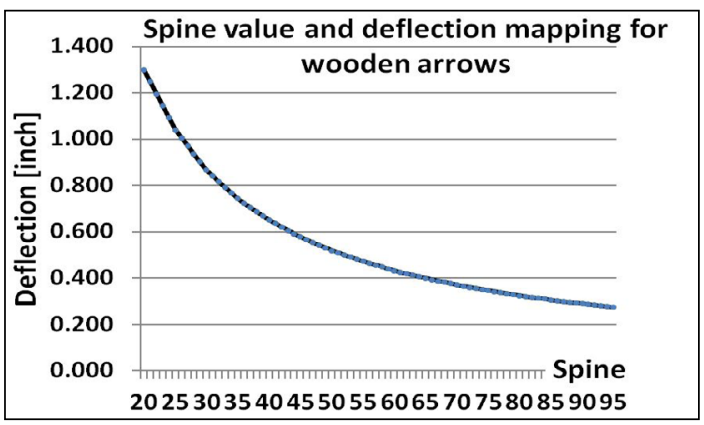

Figure 6. Classification of wooden arrows

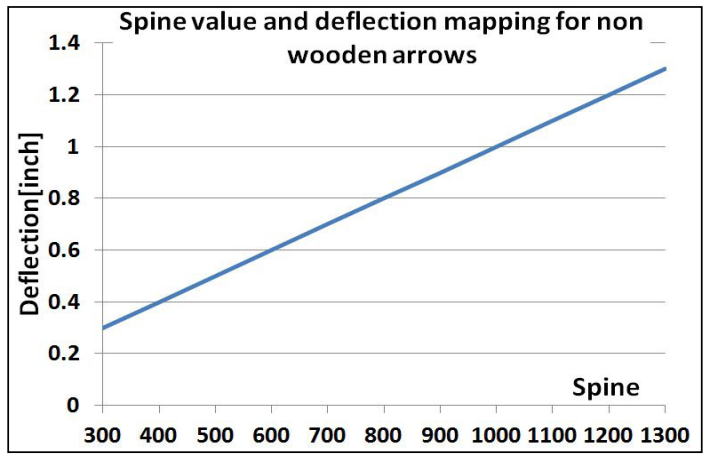

Figure 7. Classification of non wooden arrows

Table 1. Carbon arrows deflection and the matching spine values

\begin{tabular}{|c|c|c|c|c|c|c|c|c|c|c|c|c|c|}
\hline \multicolumn{14}{|c|}{ Carbon arrows } \\
\hline \multirow{2}{*}{$\begin{array}{c}\text { Carbon } \\
\text { Arrow no. }\end{array}$} & \multicolumn{3}{|c|}{ Deflection [inch] } & \multicolumn{3}{|c|}{ Deflection [mm] } & \multicolumn{2}{|c|}{ Avarage deflection } & \multicolumn{2}{|c|}{ Minimum deflection } & \multirow{2}{*}{\begin{tabular}{l|} 
Spine \\
Value
\end{tabular}} & \multicolumn{2}{|c|}{ Weight } \\
\hline & 1 & 2 & 3 & 1 & 2 & 3 & inch & $\mathrm{mm}$ & inch & $\mathrm{mm}$ & & grain & gram \\
\hline 1 & 0.568 & 0.576 & 0.560 & 14.427 & 14.630 & 14.224 & 0.568 & 14.427 & 0.560 & 14.224 & 560 & 391.800 & 25.388 \\
\hline 2 & 0.569 & 0.575 & 0.579 & 14.453 & 14.605 & 14.707 & 0.574 & 14.588 & 0.569 & 14.453 & 569 & 386.600 & 25.051 \\
\hline 3 & 0.570 & 0.574 & 0.578 & 14.478 & 14.580 & 14.681 & 0.574 & 14.580 & 0.570 & 14.478 & 570 & 390.200 & 25.285 \\
\hline 4 & 0.584 & 0.595 & 0.595 & 14.834 & 15.113 & 15.113 & 0.591 & 15.020 & 0.584 & 14.834 & 584 & 390.000 & 25.272 \\
\hline 5 & 0.588 & 0.602 & 0.591 & 14.935 & 15.291 & 15.011 & 0.594 & 15.079 & 0.588 & 14.935 & 588 & 392.400 & 25.427 \\
\hline 6 & 0.578 & 0.596 & 0.597 & 14.681 & 15.138 & 15.164 & 0.590 & 14.994 & 0.578 & 14.681 & 578 & 395.000 & 25.596 \\
\hline 7 & 0.568 & 0.587 & 0.588 & 14.427 & 14.910 & 14.935 & 0.581 & 14.757 & 0.568 & 14.427 & 568 & 392.000 & 25.401 \\
\hline 8 & 0.672 & 0.710 & 0.716 & 17.069 & 18.034 & 18.186 & 0.699 & 17.763 & 0.672 & 17.069 & 672 & 317.000 & 20.541 \\
\hline 9 & 0.687 & 0.692 & 0.692 & 17.450 & 17.577 & 17.577 & 0.690 & 17.534 & 0.687 & 17.450 & 687 & 316.400 & 20.502 \\
\hline 10 & 0.708 & 0.716 & 0.730 & 17.983 & 18.186 & 18.542 & 0.718 & 18.237 & 0.708 & 17.983 & 708 & 318.700 & 20.651 \\
\hline 11 & 0.713 & 0.718 & 0.719 & 18.110 & 18.237 & 18.263 & 0.717 & 18.203 & 0.713 & 18.110 & 713 & 311.700 & 20.198 \\
\hline 12 & 0.710 & 0.718 & 0.722 & 18.034 & 18.237 & 18.339 & 0.717 & 18.203 & 0.710 & 18.034 & 710 & 310.400 & 20.114 \\
\hline 13 & 0.693 & 0.707 & 0.724 & 17.602 & 17.958 & 18.390 & 0.708 & 17.983 & 0.693 & 17.602 & 693 & 317.300 & 20.561 \\
\hline
\end{tabular}


The deflections we have defined in the case of three series were the same as those specified by the producer.

\section{Conclusions}

In order to ensure a smooth and precise alignment of the arrow, the bending must be as favorable as possible for the equipment, shooting technique and ambient conditions. Therefore, the spine should be determined so that the archer can properly select his or her tools.

\section{References}

[1] http://preppergirluk.yolasite.com/resources/bow parts_longbow.jpg, (2017.05.05)

[2] Muttnyánszky Á.: Szilárdságtan, Műszaki Publisher, Budapest, 1981.

[3] Kemény S., Deák A.: Kísérletek tervezése és értékelése. Müszaki Publisher, Budapest, 2000. 26-54. 